\title{
Phenotyping of chronic obstructive pulmonary disease: heterogeneity and its clinical relevance
}

\author{
Tai Sun Park • Jae Seung Lee • Joon Beom Seo • \\ Yoonki Hong • Sei Won Lee • Yeon-Mok Oh • \\ Sang-Do Lee
}

Published online: 3 July 2012

(C) Springer Science+Business Media, LLC 2012

\begin{abstract}
Chronic obstructive pulmonary disease (COPD) is a spectrum of various syndromes that share airflow limitation but differ in many respects. Although airflow limitation is a defining element of COPD, forced expiratory volume in $1 \mathrm{~s}\left(\mathrm{FEV}_{1}\right)$ alone is not sufficient to explain the heterogeneity of COPD. Phenotypic characterization of clinically relevant subgroups of COPD will increase our understanding of COPD. Furthermore, a greater understanding of the complex interrelationships between the phenotypes and their environmental, genetic, molecular, and cellular basis may be achieved with comprehensive and integrated method (systems biology and network medicine). Incorporation of information obtained from these analyses into our clinical
\end{abstract}

T. S. Park · J. S. Lee $\cdot$ Y. Hong $\cdot$ S. W. Lee $\cdot$ Y.-M. Oh $•$

S.-D. Lee $(\varangle)$

Department of Pulmonary and Critical Care Medicine and Clinical

Research Center for Chronic Obstructive Airway Diseases,

Asan Medical Center, University of Ulsan College of Medicine,

88 , Olympic-ro 43-gil, Songpa-gu,

Seoul 138-736, Republic of Korea

e-mail: sdlee@amc.seoul.kr

T. S. Park

e-mail: integrin@hanmail.net

J. S. Lee

e-mail: jsdoc1186@hanmail.net

Y. Hong

e-mail: h-doc@hanmail.net

S. W. Lee

e-mail: iseiwon@gmail.com

Y.-M. Oh

e-mail: ymoh55@amc.seoul.kr

\section{J. B. Seo}

Department of Radiology, Asan Medical Center,

University of Ulsan College of Medicine,

88, Olympic-ro 43-gil, Songpa-gu,

Seoul 138-736, Republic of Korea

e-mail:seojb@amc.seoul.kr practice would allow clinicians to treat individual patients with so-called Personalized, Predictive, Preventive, and Participatory (P4) medicine. By understanding COPD heterogeneity, it may be possible in the future to detect the disease earlier and to target treatment to reduce mortality and modify the course of the disease.

Keywords Chronic obstructive pulmonary disease . Phenotype $\cdot$ Heterogeneity $\cdot$ Outcome $\cdot$ Prognosis · Therapy · Systems biology $\cdot$ Individualized medicine

\section{Introduction}

Chronic obstructive pulmonary disease (COPD) is characterized by persistent airflow limitation that is usually progressive $[1 \bullet \bullet]$. For many years, the diagnosis, assessment of severity, and therapy of COPD has been guided primarily by the degree of airflow limitation, as assessed by post-bronchodilator forced expiratory volume in $1 \mathrm{~s}\left(\mathrm{FEV}_{1}\right)$ [2]. However, although the airflow limitation is an important characteristic of COPD, it is now widely recognized that COPD represents a spectrum of overlapping diseases that have important extrapulmonary consequences [3]. Indeed, the clinical, physiologic and radiologic presentation of COPD varies significantly from patient to patient, even when the degree of airflow limitation is similar. Thus, COPD is a heterogeneous disease that can be characterized across multiple dimensions, which means that $\mathrm{FEV}_{1}$ alone is not sufficient for diagnosing, assessing, and managing this disease. As a result, recent guidelines have proposed that assessment of COPD should be based on the patient's level of symptoms, future risk of exacerbations, and the identification of comorbidites, as well as the severity of the spirometric abnormality $[1 \bullet \bullet]$.

Efficacy in the treatment of COPD can vary between patients due to the heterogeneity of the disease. However, 
at present, patients with COPD are still being treated with similar pharmacological strategies irrespective of heterogeneity. Identifying and classifying the clinically significant subgroups of COPD or "COPD phenotypes" may promote more personalized and effective treatment $[4 \bullet]$. Originally the term "phenotype" refers to the composite of the observable characteristics or traits of an organism. Phenotypes are the result of the expression of the genes of an organism, the influence of environmental factors and the interactions between these two factors. In the field of COPD, "the outward physical manifestation of patients with COPD and anything that is part of their observable structure, function, or behavior" have been described as a COPD phenotype [3]. However, not all phenotypes are clinically relevant. Therefore, from the clinical and research viewpoint, the term "COPD phenotype" needs to be refined. An international group of experts has defined the term "COPD phenotype" as "a single or combination of disease attributes that describe differences between individuals with COPD as they relate to clinically meaningful outcomes (symptoms, exacerbations, response to therapy, rate of disease progression, or death) [5••]." This definition provides a framework of categorizing unique characteristics of patients with COPD into distinct prognostic and therapeutic subgroups. Furthermore, identifying distinct subgroups of COPD may promote research into the etiological mechanisms behind the COPD phenotype, which in turn will provide information at the genotype, molecular, cellular, and phenotype levels that could be incorporated into our understanding and management of COPD.

A variety of methods have been used to explore the different phenotypes of COPD. The classic two extreme clinical phenotypes of "blue bloater" or "pink puffer" were based on rather subjective clinical assessment of patients and are not sufficient for categorizing various COPD phenotypes. Phenotypic classification based on inter-related characteristics would be theoretically attractive. In recent years, cluster analysis has been used for the classification of different clinical phenotypes of COPD. However, groups classified by cluster analysis do not prove that they represent distinct phenotypes that are clinically meaningful, and simple robust classification rules which accurately predict the phenotype for a particular patient have not been developed yet. Thus we classify the potential COPD phenotypes into one of three categories: clinical, physiologic and radiologic, and present the clinical relevance of those potential COPD phenotypes in this review.

\section{Clinical phenotypes}

Various clinical factors of COPD have been reported to be associated with disease presentations. Clinical phenotypes are determined by their symptomatic or epidemiologic significance. Individuals within a unique clinical phenotype would have a similar underlying pathophysiologic mechanism. Therefore, in many aspects, clinical phenotypes can overlap with physiologic phenotypes.

\section{Sex}

The prevalence of COPD in women is currently increasing and several recent studies have suggested that there are sex differences in the epidemiology and clinical presentation of COPD. Women may be at greater risk of smoking-induced lung function impairment for the same level of tobacco exposure. Women with COPD report more dyspnea and lower selfreported health status compared with men after adjusting for smoking burden and lung function [6]. Although they have lower mortality rates [7], rates of exacerbation of COPD are higher [8] and long-term oxygen therapy is less effective than men [9]. Higher prevalence of anxiety is also noted [10]. The biological mechanisms that explain these differences are not clear but may relate to susceptibility to the effects of cigarette smoke, decreased clearance of the toxins, and an exaggerated immune and hormonal response [11]. More research is needed to determine the implications of these differences with regard to therapy.

\section{Body mass index}

Unexplained weight loss in patients with COPD is frequent and the association between low body mass index (BMI) and poor prognosis is a common clinical observation. Weight loss is an important determinant of symptoms, disability and quality of life [12]. Furthermore, low BMI is an independent risk factor for mortality [13] and a profound decline in $\mathrm{FEV}_{1}$ over time in subjects with COPD [14]. However, BMI appears to have little impact on acute exacerbation of COPD [15]. Targeted therapy with nutritional support, pulmonary rehabilitation and subsequent reversal of weight loss for COPD patients with low BMI may promise improved outcomes, including increased muscle strength and exercise capacity, as well as increased survival [13]. However, the studies that have tested this notion have not been encouraging [16] and it appears that nutritional supplementation alone may not be sufficient. It should also be noted that weight loss is not necessarily due to inadequate nutrition. Indeed, it can arise from systemic inflammation, as discussed below. Further research investigating the role of systemic inflammation in the poor prognosis of patients with COPD who have undergone unexplained weight loss is warranted.

\section{Chronic bronchitis}

The early epidemiologic studies by Fletcher and coworkers suggested that chronic bronchitis was not associated with a 
decline in lung function, as measured by the annual decline of $\mathrm{FEV}_{1}$ [17]. However, subsequent studies found an association between mucus hypersecretion and a steeper decline in $\mathrm{FEV}_{1}$ [18]. In addition, chronic cough and sputum expectoration are associated with increased rates of mortality [19]. Moreover, patients with chronic bronchitis have worse respiratory symptoms, a poorer health status, greater physical activity limitation, and a higher risk of exacerbation [20]. Therefore, this group may need more directed and targeted therapy, such as anti-inflammatory treatment. This could include phosphodiesterase-4 (PDE-4) inhibitors such as roflumilast. This oral selective PDE-4 inhibitor was shown to reduce moderate to severe exacerbations treated with corticosteroids by $15-20 \%$ and to improve pulmonary function in a subgroup of patients with chronic bronchitis, severe or very severe COPD, and a history of exacerbation $[21 \bullet, 22]$. Furthermore, the mode of action of roflumilast may provide a unique approach to targeting the inflammatory process underlying COPD compared with other currently available medication. Interestingly, recent studies have shown that long-term use of antibiotics can reduce the exacerbation rate [23]. These antibiotics are mostly macrolides, which may have anti-inflammatory effects in addition to their antibiotic effects. However, due to the unfavorable balance between the benefits and side effects of antibiotics, prophylactic and continuous use of these drugs is currently not recommended.

\section{Dyspnea}

Dyspnea is a cardinal symptom of COPD that can significantly impact health status of the patient. The level of dyspnea varies considerably for the same degree of airflow limitation [24]. It also correlates more significantly with survival than $\mathrm{FEV}_{1}$ [25]. Measurement of dyspnea in addition to degree of airflow limitation is now noted for predicting survival and assessing the complex systemic nature of COPD. The BODE method gives a composite score (Body mass index, Obstruction, Dyspnea, and Exercise) that is a better predictor of subsequent survival than any component singly [26].

Frequent exacerbators

Acute exacerbations of COPD (AECOPDs) are critical events in COPD and place significant socioeconomic burdens on the health care system [27]. An AECOPD is characterized by a worsening of the patient's respiratory symptoms beyond normal day-to-day variations that necessitates a change in regular medication $[1 \bullet \bullet$. AECOPDs episodes result in a significant deterioration in health status [28], accelerate the rate of decline of lung function [29], and are associated with significant mortality [30]. The incidence of AECOPDs does not have a normal distribution, and there are several reports that some patients appear to be particularly prone to suffer AECOPDs [31••]. These observations suggest the existence of an important subgroup of patients with COPD. Currently, patients with two or more AECOPDs per year are considered as "frequent exacerbators," whose treatment may be differentiated [31••, 32]. Recent studies by Hurst et al. have shown that exacerbations become more frequent and more severe as the severity of underlying COPD increases and that the most important determinant of frequent exacerbations is a history of exacerbations [32]. Other risk factors associated with repeated exacerbations are older age, severe COPD (greater baseline dyspnea, low $\mathrm{FEV}_{1}$, and low $\mathrm{PaO}_{2}$ ), inflammation (greater airway and systemic inflammation), bacterial load, chronic bronchial hypersecretion and comorbidities (cardiovascular diseases, anxietydepression, and myopathy) [31••]. The number of exacerbations and hospitalizations in these patients can be reduced by smoking cessation, influenza and pneumococcal vaccinations, and treatment with long-acting inhaled bronchodilators (with or without inhaled corticosteroids) and possibly also PDE-4 inhibitors $[21 \cdot 33,34]$. Identifying of the patients with COPD who predispose to exacerbations and closely following up them will help to decrease the exacerbations, the mortality rate, and the burden on the healthcare system.

\section{Systemic inflammation}

COPD is a chronic inflammatory condition of the airways and the lungs, and various inflammatory cells and mediators have long been considered to play a significant role in the pathogenesis of the disease. The roles of inflammation and pro-inflammatory cytokines may extend beyond the lungs and play a part in the systemic effects of the disease and associated comorbidities. Patients with clinically stable COPD exhibit low-grade systemic inflammation, such as leukocytosis and increased levels of serum C-reactive protein, interleukin 6 and tumor necrosis factor $\alpha$ [35], and the levels of biomarkers are further increased during exacerbations [36]. This systemic inflammation can be reduced by steroid therapy (both oral and inhaled). However, the impact of pharmacologically reducing systemic inflammation on clinically relevant outcomes of COPD remains unclear [37]. The systemic inflammation in patients with COPD varies and also appears in other chronic diseases. It is even observed in the normal process of aging. Thus, to date, it is unclear how systemic inflammation contributes to the pathophysiology of many systemic effects of COPD.

\section{Comorbidities}

COPD often coexists with comorbid diseases which may have a significant impact on prognosis [38]. Skeletal muscle wasting and dysfunction are seen in many patients with 
COPD. Several factors are likely to promote reduced muscle mass in COPD, including hypoxia, use of oral and inhaled corticosteroids, systemic inflammation, oxidative stress, inactivity, and poor diet. It can contribute to exercise intolerance and poor health status in patients with COPD [39]. Various methods for estimating skeletal muscle depletion can help to determine the prognosis of patients with COPD $[40,41]$. For this phenotype, pulmonary rehabilitation may be helpful to improve the exercise capacity and health status in COPD [42]. Cardiovascular disease is a major comorbidity in COPD and is probably the most frequent and most important disease that coexists with COPD $[43,44]$. Recently, several observational studies exploring the efficacy of statins and angiotensin converting enzyme inhibitors or angiotensin II receptor blockers revealed these drugs could reduce the overall cardiovascular risks, morbidity, and mortality of patients with COPD [45, 46]. Osteoporosis is also a major comorbidity in COPD. Along with the direct impact of osteoporosis on morbidity and mortality, vertebral fracture can result in a decreased forced vital capacity (FVC) [47]. Cigarette smoking, high corticosteroids use, low BMI, reduced mobility and muscle strength, and systemic inflammation all contribute to the development of osteoporosis in COPD. Thus, systemic corticosteroids should be avoided if possible, and bisphosphonates as well as pulmonary rehabilitation may be helpful. In addition, anxiety/depression, metabolic syndrome/diabetes and lung cancer are frequently seen in patients with COPD. All of these are associated with a poor prognosis $[43,48,49]$. Most of comorbidities correlate poorly with the degree of airflow limitation. Although these comorbidities could be caused by either smoking or aging, they may also develop as a result of the systemic inflammation, which is the extra-pulmonary effect of COPD [35]. However, in general, COPD and its comorbidities do not influence each other for treatment.

\section{Overlap syndrome}

It is necessary to distinguish between asthma and COPD to provide appropriate therapy for patients. However, within the spectrum of chronic airway obstruction, there are individuals who share features of both asthma and COPD, especially in older age group. A large population study showed that $19 \%$ of patients with chronic airway obstruction had more than one obstructive lung disease condition, and the proportion of patients who had an overlapping diagnosis rose with age [50]. Indeed, Kim et al. demonstrated that there is an intermediate type between asthma and COPD whose clinical characteristics differ significantly [51]. Jo et al. also showed that elderly subjects with obstructive lung disease could be classified into three phenotypes that did not strictly meet the criteria of either asthma or COPD [52]. Overlap syndrome is characterized by the coexistence of increased variability of airflow in a patient with incompletely reversible airway obstruction [53]. Patients with overlap syndrome report worse health-related quality of life and experience more frequent and severe exacerbations [54]. Moreover, coexisting COPD and asthma have a higher risk of death than COPD or asthma singly [55]. Overlap syndrome can develop due to an accelerated decline in lung function or incomplete lung growth in children, or both: increasing age, bronchial hyper-responsiveness, tobacco smoke exposure, asthma and lower respiratory infections/ exacerbations are all significant risk factors for both accelerated loss of lung function and incomplete lung growth [53]. Since patients with overlap syndrome are usually excluded from clinical pharmaceutical trials, it is necessary to extend them to clinical trial and to recognize the overlap syndrome as a part of the chronic airway obstructive disease spectrum.

\section{Physiologic phenotypes}

Physiologic phenotypes of COPD are defined by pulmonary function as well as functional capacity of patients with COPD. They may reflect unique biologic processes and consequently potential opportunities for targeted interventions. Various physiologic measurements such as spirometric indices, lung volume, diffusing capacity and hypoxemia are included in this category.

Airflow limitation and rapid decline in $\mathrm{FEV}_{1}$

The degree of airflow limitation, as measured by $\mathrm{FEV}_{1}$, is the most common way to categorize and stage patients with COPD. However, although $\mathrm{FEV}_{1}$ is useful for predicting health status [56], the development of exacerbations [32], and mortality [57], there is only a weak correlation between $\mathrm{FEV}_{1}$ and the symptoms of COPD and health-related quality of life [58]. It is also increasingly being realized that $\mathrm{FEV}_{1}$ alone is not the best predictor of mortality [26]. Although $\mathrm{FEV}_{1}$ declines with normal aging by approximately $30 \mathrm{~mL}$ per year, the rate of decline in certain susceptible smokers is greater than $60 \mathrm{~mL}$ per year. A rapid decline in $\mathrm{FEV}_{1}$ is associated with increased morbidity, mortality and hospitalization rates [59]. Along with smoking, airway hyperresponsiveness, repeated respiratory infections, concomitant respiratory diseases, emphysema extent on computed tomography and genetic factors may contribute to the accelerated decline of $\mathrm{FEV}_{1}$, and only smoking cessation has been shown to be effective in reducing the rate of $\mathrm{FEV}_{1}$ decline $[60,61]$.

Bronchodilator responsiveness and airway hyperresponsiveness

Although irreversible airflow limitation is an important characteristic of COPD, the majority of patients with COPD 
still have meaningful bronchodilator responsiveness (BDR) [62]. BDR is usually assessed by the improvement in $\mathrm{FEV}_{1}$ or FVC after inhalation of a short acting beta- 2 agonist and/or anti-cholinergics [63]. In patients with COPD, different response patterns to bronchodilator exists, such that some patients show improvement principally in expiratory flow indices (flow responders), whereas others respond by improvement of lung volume (volume responders). These different response patterns to bronchodilator may be associated with the degree of emphysema and air trapping [64]. However, BDR is poorly reproducible in patients with COPD and variable significantly from patient to patient. It also cannot predict the rate of decline in $\mathrm{FEV}_{1}$, health status impairment, and exacerbations [65]. Thus, the significance of BDR remains unclear. In contrast to BDR, airway hyperresponsiveness is an important predictor for an accelerated decline in $\mathrm{FEV}_{1}$ [66]. Indeed, airway hyper-responsiveness is an independent risk factor for the development of smoking-induced irreversible airflow limitation, and is second only to cigarette smoking as the leading risk factor for COPD [67].

Hyperinflation, low diffusing capacity, and hypoxemia

Expiratory airflow limitation causes hyper-inflated lung in patients with COPD, which results in increased functional residual capacity with consequent reduction in inspiratory capacity. Hyperinflation correlates better with exercise impairment than with airflow limitation [68], and can be used to predict mortality when the inspiratory capacity to total lung capacity ratio is employed [69]. Long-acting bronchodilator can improve dyspnea and exercise capacity by decreasing hyperinflation and increasing inspiratory capacity. Singlebreath diffusing capacity of the lung for carbon monoxide $\left(\mathrm{DL}_{\mathrm{CO}}\right)$ represents the best pulmonary function test to assess the integrity of the pulmonary capillary bed [70]. A low $\mathrm{DL}_{\mathrm{CO}}$ is related to the severity of emphysema, hypoxemia, and functional impairment [71-73]. In addition, it has shown to be a predictor of mortality after lung volume reduction surgery [74]. However, a low $\mathrm{DL}_{\mathrm{CO}}$ is not a specific phenotype of COPD but reflects the functional impact of emphysema, airflow limitation, and pulmonary capillary bed destruction. The ventilation and perfusion mismatch that is caused by airway obstruction and emphysema is the main cause of hypoxemia in patients with COPD. Chronic hypoxemia is associated with the development of pulmonary arterial hypertension, secondary polycythemia, systemic inflammation, and skeletal muscle dysfunction. Consequently, it leads to a poor quality of life, exercise intolerance, increased cardiovascular morbidity, and a higher mortality rate [75]. Long-term oxygen therapy is one of the few interventions that can prolong survival in hypoxemic patients with COPD [76].
Pulmonary arterial hypertension

The development of pulmonary arterial hypertension (PAH) is a poor prognostic sign in patients with COPD as it affects both mortality and quality of life [77]. The level of pulmonary arterial pressure (PAP) is one of the best prognostic factors in COPD patients who receive long-term oxygen therapy [78]. While PAH in COPD is thought to be due mainly to pulmonary hypoxic vasoconstriction, correction of the hypoxia alone is not sufficient to improve PAH. This may be because PAH involves extensive vascular remodeling within all layers of the pulmonary arterial wall rather than just medial hypertrophy [79]. In addition, lung function parameters correlate poorly with PAP, which suggests that factors other than airways obstruction and/or loss of alveolar surface may play a role in its etiology. Indeed, disproportionate PAH are observed in COPD patients with moderate airflow limitation. Low hemoglobin concentration may be associated with elevated PAP in this group [80]. Yet, there are few therapies that have been developed for PAH in COPD. Endothelin receptor antagonists, phosphodiesterase inhibitors, and simvastatin may be helpful for PAH in COPD as well as in idiopathic PAH and need to be evaluated through clinical trials $[81,82]$.

\section{Radiologic phenotypes}

Recent advances in computed tomography (CT) suggest that it might be a useful tool for evaluating both qualitatively and quantitatively the severity, extent, and distribution of the disease components of COPD such as emphysema and airway wall thickening [83]. CT scanning can differentiate these underlying pathological subtypes and has emerged as an important and noninvasive tool in phenotyping COPD. Recent studies reported that radiologic characterizations of COPD are associated with various clinical outcomes, as follows [84]. However, the role of CT imaging in phenotyping COPD beyond lung function is not fully determined.

\section{Emphysema}

CT can detect earlier emphysema that can be detected by spirometry or diffusing capacity and many studies have addressed the ability of CT to accurately quantify the extent and severity of pulmonary emphysema [85]. CT emphysema severity is associated with lower BMI, worse health status, BODE index and a rapid decline in $\mathrm{FEV}_{1}[71,84,86]$. Furthermore, it was shown to be predictive of a poorer pulmonary function response to treatment with a long-acting beta-agonist and inhaled steroid [87]. Besides the extent of emphysema, the distribution of emphysema such as lower predominance can predict a high risk of mortality $[88,89]$. 
Airway disease

Airway wall thickening can be assessed quantitatively by measuring wall area and lumen area on volumetric CT. Increased airway wall thickness is associated with a worse quality of life and a poorer response to treatment with inhaled corticosteroids [71, 84]. Moreover, greater airway wall thickness and emphysema percentage are associated with frequent COPD exacerbations, independent of the severity of airflow limitation [90]. This phenotype may be predicted by a genetic marker such as ADRB2 gene polymorphism, which may be associated with COPD susceptibility and the bronchodilator response [91].
Integration of physiologic and $\mathrm{CT}$ data

It may be useful to integrate physiologic and CT features of COPD patients in a multidimensional approach to phenotyping patients with COPD. For example, lung volume reduction surgery (LVRS) is more effective than medical therapy for patients with predominantly upper-lobe emphysema and low exercise capacity prior to treatment [92]. By contrast, LVRS results in more mortality than medical management when it is used to treat severe emphysema patients with lower $\mathrm{FEV}_{1}$ and either homogeneous emphysema on $\mathrm{CT}$ or reduced $\mathrm{DL}_{\mathrm{CO}}$ [74]. In addition, combined assessment of COPD with emphysema and $\mathrm{FEV}_{1}$ can predict the responses to therapy [93].

Table 1 Potential phenotypes in COPD and their clinical relevance

\begin{tabular}{|c|c|c|c|c|c|c|}
\hline Phenotypes & $\begin{array}{l}\text { Symptoms or } \\
\text { quality of life }\end{array}$ & Exacerbations & $\begin{array}{l}\text { Rate of disease } \\
\text { progression }\end{array}$ & Mortality & Targeted interventions & References \\
\hline \multicolumn{7}{|l|}{ Clinical } \\
\hline Female sex & Poor & Frequent & & Low & Smoking cessation & {$[6-10]$} \\
\hline Low BMI & Poor & & Rapid & High & Nutrition, rehabilitation & [12-15] \\
\hline $\begin{array}{l}\text { Chronic } \\
\text { bronchitis }\end{array}$ & Poor & Frequent & Rapid & High & PDE-4 inhibitor & {$[18-22]$} \\
\hline Dyspnea & Poor & Frequent & & High & $\mathrm{BD}$, rehabilitation & {$[25,31]$} \\
\hline $\begin{array}{l}\text { Frequent } \\
\text { exacerbator } \\
\text { Comorbidities }\end{array}$ & Poor & Frequent & Rapid & High & $\begin{array}{l}\text { Smoking cessation, vaccination, BD, } \\
\text { ICS, PDE-4 inhibitor }\end{array}$ & {$[21,28-34]$} \\
\hline $\begin{array}{l}\text { Skeletal muscle } \\
\text { wasting }\end{array}$ & Poor & Frequent & & High & Rehabilitation & {$[31,39-42]$} \\
\hline Cardiovascular & & Frequent & & High & Statin, ACEi or ARB & $\begin{array}{l}{[31,43,45,} \\
\quad 46]\end{array}$ \\
\hline Osteoporosis & Poor & & & High & Specific therapy & {$[47]$} \\
\hline $\begin{array}{l}\text { Anxiety and } \\
\text { depression }\end{array}$ & Poor & Frequent & & High & Specific therapy & [48] \\
\hline $\begin{array}{l}\text { Overlap } \\
\text { syndrome } \\
\text { Physiologic }\end{array}$ & Poor & Frequent & Rapid & High & $\mathrm{BD}, \mathrm{ICS}$ & {$[53,55]$} \\
\hline $\begin{array}{l}\text { Degree of airflow } \\
\text { limitation }\end{array}$ & Weak correlation & Frequent & & High & BD, ICS, PDE-4 inhibitor & {$[32,56-58]$} \\
\hline Rapid decliner & & & Rapid & High & Smoking cessation & [59-61] \\
\hline AHR & & & Rapid & & $\mathrm{BD}, \mathrm{ICS}$ & {$[65-67]$} \\
\hline Hyperinflation & Poor & & & High & $\mathrm{BD}$ & {$[68,69]$} \\
\hline Low $\mathrm{DL}_{\mathrm{CO}}$ & Poor & & & High & Avoid LVRS & {$[72,74]$} \\
\hline PAH & Poor & & & High & $\begin{array}{l}\text { Endothelin receptor antagonist, PDE- } \\
4 \text { inhibitor, statin }\end{array}$ & {$[77,81-82]$} \\
\hline Hypoxemia & Poor & & & High & LTOT & {$[75,76]$} \\
\hline \multicolumn{7}{|l|}{ Radiologic } \\
\hline Emphysema & Poor & Frequent & Rapid & High & LVRS, AAT replacement & $\begin{array}{l}{[71,74,} \\
84-89, \\
92]\end{array}$ \\
\hline Airway disease & Poor & Frequent & & & $\mathrm{BD}$ & {$[71,84,90]$} \\
\hline
\end{tabular}

$A A T$ alpha-1 antitrypsin; $A C E i$ angiotensin-converting enzyme inhibitor; $A H R$ airway hyper-responsiveness; $A R B$ angiotensin II receptor blocker; $B D$ bronchodilator; $B M I$ body mass index; $D L_{C O}$ diffusing capacity for carbon monoxide; ICS inhaled corticosteroid; $L T O T$ long-term oxygen therapy; LVRS lung volume reduction surgery; $P A H$ pulmonary arterial hypertension; $P D E-4$ phosphodiesterase-4 


\section{Future perspectives}

In the past decades, COPD was classified on the basis of the degree of airflow limitation. However, it is now apparent that COPD is multidimensional and complex diseases that consist of several different phenotypes (clinical, physiologic and radiologic) with distinct clinical outcomes (symptoms or quality of life, frequency of exacerbations, rate of disease progression, and mortality) and with potential interventions that are specifically targeted to defined phenotypes (Table 1). Delineating heterogeneity and complexity of COPD by describing the relationships between clinical, physiologic and radiologic domains of the disease will advance therapeutic interventions for a specific phenotype. In this way, future treatments that are targeted towards specific phenotypes may improve clinically relevant outcomes.

To develop novel biomarkers and targeted therapeutic interventions in COPD, it is necessary to improve our understanding of the interrelationships between phenotypes and their environmental, genetic, molecular and cellular basis. The interactions between genetic and environmental risk factors result in different phenotypes through several molecular and cellular pathophysiologic cascades, in other words, intermediate pathophenotypes (or endotypes). These cascades involve inflammation, oxidative stress, protease/antiprotease imbalance, apoptosis, senescence, innate and acquired immunity abnormalities, and abnormal repair (Fig. 1) [95]. While it remains challenging to understand precisely how this complex mixture of factors interact, comprehensive and integrated methods (namely systems biology approaches and network medicine) can be used to unravel the complex networks that exist between genes, proteins, RNA, and small molecules that interact at biochemical and physical levels [95]. Indeed, biomarkers such as Clara cell secretory protein-16 (CC-16), surfactant protein (SP)-D and serum amyloid A (SAA) have been reported as candidate biomarkers in COPD [96-98]. However, there are no well validated molecular biomarkers related to clinically meaningful outcomes in COPD. It is anticipated that the recent technological and analytical advances in the research strategies in human disease complexity will lead us to the identification of genetic markers for risk assessment, biomarkers for diagnosis and therapeutic targets. During this process, it may possible to develop simple validated classification criteria for COPD phenotypes that would allow clinicians to treat individual patients with Personalized, Predictive, Preventive, and Participatory (P4) medicine [99••]. Recent international guidelines for COPD have suggested individualized treatment for patients with COPD according to air flow limitation, dyspnea and exacerbation risk. We expect that more potential phenotypes discussed in this review will be validated and new treatment guidelines according to each phenotype will be emerged in the future.

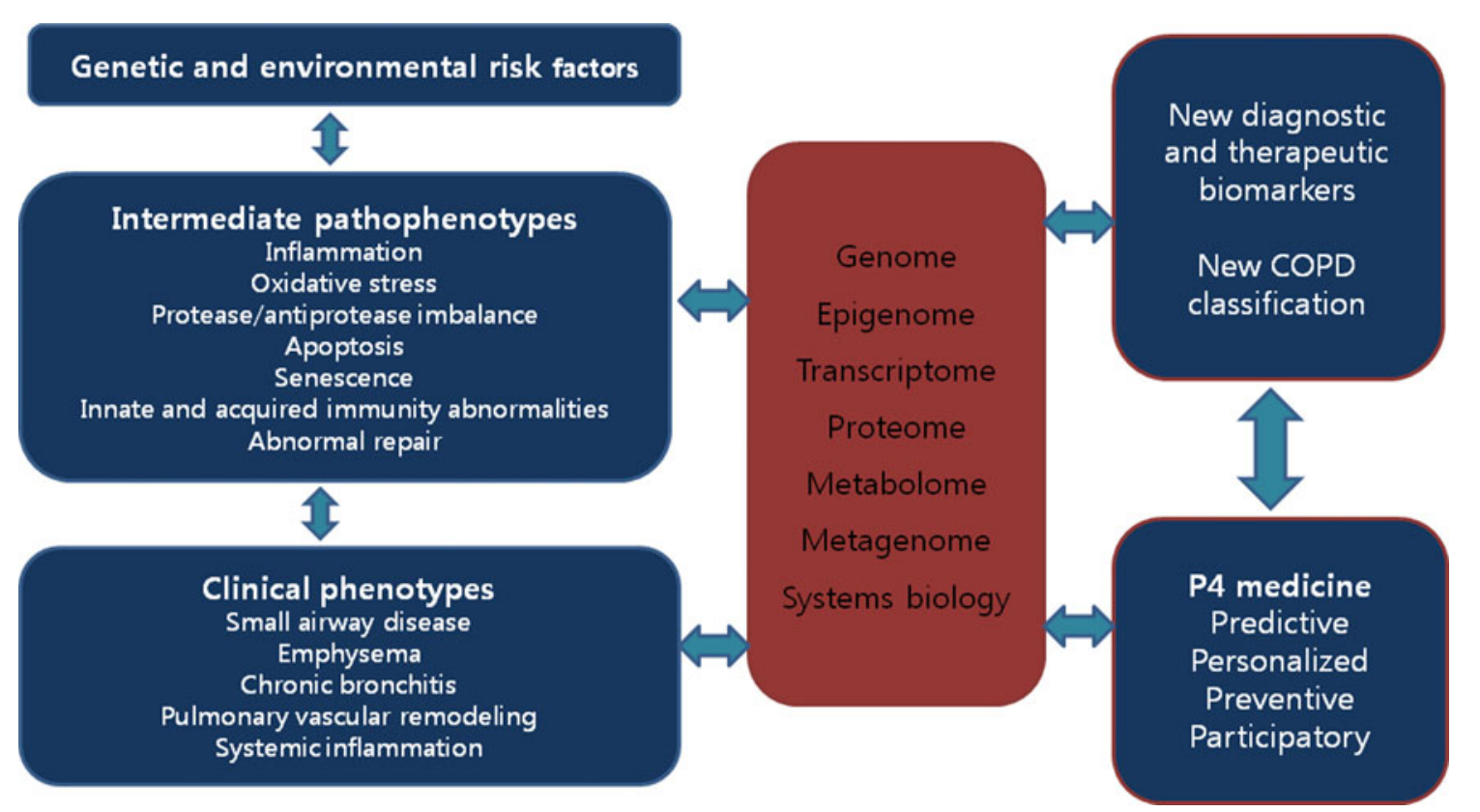

Fig. 1 COPD phenotypes and their potential clinically relevant outcomes. Systems biology approaches will aid our understanding of the interrelationships between clinical phenotypes and their environmental, genetic, molecular, and cellular basis. This information will allow
COPD subtypes to be identified, which will make it possible for clinicians to treat individual patients with P4 medicine. (Modified from $[94,95,99 \cdot \bullet]$.) 


\section{Conclusions}

COPD is a spectrum of various syndromes that share a defining physiologic feature (airflow limitation) but differ in many respects. By understanding COPD heterogeneity, it may become possible to detect the disease earlier and to treat specifically for defined phenotypic groups, rather than for COPD in general. Eventually, improved survival and delayed disease progression could be made possible.

Acknowledgments This study was supported by a grant from the Korea Healthcare Technology R\&D Project, Ministry for Health, Welfare and Family Affairs, Republic of Korea (A102065).

Disclosure T. S. Park: none; J. S. Lee: none; Y. Hong: none; S. W. Lee: none; J. B. Seo: has been an investigator in a governmentsponsored study (2006-2008 Korea Science and Engineering Foundation); Y. -M. Oh: has been an investigator in university-sponsored studies (Asan Institute for Life Science, University of Ulsan College of Medicine) and an industry sponsored study (MSD Korea, and AstraZeneca Korea) and has participated as a speaker at scientific meetings organized and financed by various pharmaceutical companies (Handok, GlaxoSmithKline, AstraZeneca Korea, MSD Korea and Boehringer Ingelheim) and a magazine company (Korea Doctors' Weekly); S. -D. Lee: serves as a consultant to GlaxoSmithKline and has participated as a speaker at scientific meetings organized and financed by various pharmaceutical companies (GlaxoSmithKline, Nycomed, AstraZeneca Korea and Boehringer Ingelheim).

\section{References}

Papers of particular interest have been highlighted as:

- Of importance

- Of outstanding importance

1. • Global Initiative for Chronic Obstructive Lung Disease. Global strategy for the diagnosis, management, and prevention of chronic obstructive pulmonary disease (Revised 2011). Available at http:// www.goldcopd.org/uploads/users/files/GOLD_Report_2011_ Feb21.pdf. Accessed February 2012. This is a up-to-date document for diagnosis, management, and prevention of COPD.

2. Rabe KF, Hurd S, Anzueto A, et al. Global strategy for the diagnosis, management, and prevention of chronic obstructive pulmonary disease: GOLD executive summary. Am J Respir Crit Care Med. 2007;176:532-55.

3. Friedlander AL, Lynch D, Dyar LA, et al. Phenotypes of chronic obstructive pulmonary disease. COPD. 2007;4:355-84.

4. - Anderson D, Macnee W. Targeted treatment in COPD: a multisystem approach for a multi-system disease. Int J Chron Obstruct Pulmon Dis. 2009;4:321-35. This is a comprehensive review on targeted treatment in $C O P D$

5. • Han MK, Agusti A, Calverley PM, et al. Chronic obstructive pulmonary disease phenotypes: the future of COPD. Am J Respir Crit Care Med. 2010;182:598-604. This is the first article which proposes that COPD phenotypes should have clinically meaningful outcomes.

6. Martinez FJ, Curtis JL, Sciurba F, et al. Sex differences in severe pulmonary emphysema. Am J Respir Crit Care Med. 2007;176: 243 52.
7. National Heart, Lung, and Blood Institute. Morbidity and mortality chartbook on cardiovascular, lung and blood diseases. Available at http://www.nhlbi.nih.gov/resources/docs/cht-book.htm. Accessed February 2012.

8. de Torres JP, Casanova C, Hernandez C, et al. Gender and COPD in patients attending a pulmonary clinic. Chest. 2005;128:2012-6.

9. Foy CG, Rejeski WJ, Berry MJ, et al. Gender moderates the effects of exercise therapy on health-related quality of life among COPD patients. Chest. 2001;119:70-6.

10. Gudmundsson G, Gislason T, Janson C, et al. Depression, anxiety and health status after hospitalisation for COPD: a multicentre study in the Nordic countries. Respir Med. 2006;100:87-93.

11. Sin DD, Cohen SB, Day A, et al. Understanding the biological differences in susceptibility to chronic obstructive pulmonary disease between men and women. Proc Am Thorac Soc. 2007;4:671-4.

12. Shoup R, Dalsky G, Warner S, et al. Body composition and healthrelated quality of life in patients with obstructive airways disease. Eur Respir J. 1997;10:1576-80.

13. Schols AM, Slangen J, Volovics L, et al. Weight loss is a reversible factor in the prognosis of chronic obstructive pulmonary disease. Am J Respir Crit Care Med. 1998;157:1791-7.

14. Casanova C, de Torres JP, Aguirre-Jaime A, et al. The progression of chronic obstructive pulmonary disease is heterogeneous: the experience of the BODE cohort. Am J Respir Crit Care Med. 2011;184:1015-21.

15. Miravitlles M, Guerrero T, Mayordomo C, et al. Factors associated with increased risk of exacerbation and hospital admission in a cohort of ambulatory COPD patients: a multiple logistic regression analysis. The EOLO Study Group. Respiration. 2000;67:495-501.

16. Ferreira IM, Brooks D, Lacasse Y, et al. Nutritional support for individuals with COPD: a meta-analysis. Chest. 2000;117:672-8.

17. Fletcher C, Peto R. The natural history of chronic airflow obstruction. Br Med J. 1977;1:1645-8.

18. Vestbo J, Prescott E, Lange P. Association of chronic mucus hypersecretion with $\mathrm{FEV}_{1}$ decline and chronic obstructive pulmonary disease morbidity. Copenhagen City Heart Study Group. Am J Respir Crit Care Med. 1996;153:1530-5.

19. Pelkonen M, Notkola IL, Nissinen A, et al. Thirty-year cumulative incidence of chronic bronchitis and COPD in relation to 30-year pulmonary function and 40-year mortality: a follow-up in middleaged rural men. Chest. 2006;130:1129-37.

20. Kim V, Han MK, Vance GB, et al. The chronic bronchitic phenotype of COPD: an analysis of the COPDGene Study. Chest. 2011;140:626-33.

21. - Calverley PM, Rabe KF, Goehring UM, et al. Roflumilast in symptomatic chronic obstructive pulmonary disease: two randomised clinical trials. Lancet. 2009;374:685-94. This article shows that targeted specific therapies could improve management of COPD.

22. Lee SD, Hui DS, Mahayiddin AA, et al. Roflumilast in Asian patients with COPD: a randomized placebo-controlled trial. Respirology. 2011;16:1249-57.

23. Albert RK, Connett J, Bailey WC, et al. Azithromycin for prevention of exacerbations of COPD. N Engl J Med. 2011;365:689-98.

24. Wolkove N, Dajczman E, Colacone A, et al. The relationship between pulmonary function and dyspnea in obstructive lung disease. Chest. 1989;96:1247-51.

25. Nishimura K, Izumi $T$, Tsukino $M$, et al. Dyspnea is a better predictor of 5-year survival than airway obstruction in patients with COPD. Chest. 2002;121:1434-40.

26. Celli BR, Cote CG, Marin JM, et al. The body-mass index, airflow obstruction, dyspnea, and exercise capacity index in chronic obstructive pulmonary disease. N Engl J Med. 2004;350:1005-12.

27. Mathers CD, Loncar D. Projections of global mortality and burden of disease from 2002 to 2030. PLoS Med. 2006;3: e442. 
28. Seemungal TA, Donaldson GC, Paul EA, et al. Effect of exacerbation on quality of life in patients with chronic obstructive pulmonary disease. Am J Respir Crit Care Med. 1998;157:1418-22.

29. Donaldson GC, Seemungal TA, Bhowmik A, et al. Relationship between exacerbation frequency and lung function decline in chronic obstructive pulmonary disease. Thorax. 2002;57:847-52.

30. Soler-Cataluna JJ, Martinez-Garcia MA, Roman Sanchez P, et al. Severe acute exacerbations and mortality in patients with chronic obstructive pulmonary disease. Thorax. 2005;60:925-31.

31. • Soler-Cataluna JJ, Rodriguez-Roisin R. Frequent chronic obstructive pulmonary disease exacerbators: how much real, how much fictitious? COPD. 2010;7:276-84. This is a comprehensive review on the presence of frequent exacerbations of COPD.

32. Hurst JR, Vestbo J, Anzueto A, et al. Susceptibility to exacerbation in chronic obstructive pulmonary disease. N Engl J Med. 2010; 363:112838.

33. Calverley PM, Anderson JA, Celli B, et al. Salmeterol and fluticasone propionate and survival in chronic obstructive pulmonary disease. N Engl J Med. 2007;356:775-89.

34. Tashkin DP, Celli B, Senn S, et al. A 4-year trial of tiotropium in chronic obstructive pulmonary disease. N Engl J Med. 2008;359: 1543-54.

35. Agusti AG, Noguera A, Sauleda J, et al. Systemic effects of chronic obstructive pulmonary disease. Eur Respir J. 2003;21:347-60.

36. Hurst JR, Perera WR, Wilkinson TM, et al. Systemic and upper and lower airway inflammation at exacerbation of chronic obstructive pulmonary disease. Am J Respir Crit Care Med. 2006; 173:71-8.

37. Agusti A. Systemic effects of chronic obstructive pulmonary disease: what we know and what we don't know (but should). Proc Am Thorac Soc. 2007;4:522-5.

38. Barnes PJ, Celli BR. Systemic manifestations and comorbidities of COPD. Eur Respir J. 2009;33:1165-85.

39. Mostert R, Goris A, Weling-Scheepers C, et al. Tissue depletion and health related quality of life in patients with chronic obstructive pulmonary disease. Respir Med. 2000;94:859-67.

40. Pinto-Plata VM, Cote $\mathrm{C}$, Cabral H, et al. The 6-min walk distance: change over time and value as a predictor of survival in severe COPD. Eur Respir J. 2004;23:28-33.

41. Vestbo J, Prescott E, Almdal T, et al. Body mass, fat-free body mass, and prognosis in patients with chronic obstructive pulmonary disease from a random population sample: findings from the Copenhagen City Heart Study. Am J Respir Crit Care Med. 2006;173:79-83.

42. Maltais F, LeBlanc P, Simard C, et al. Skeletal muscle adaptation to endurance training in patients with chronic obstructive pulmonary disease. Am J Respir Crit Care Med. 1996;154:442-7.

43. Mannino DM, Thorn D, Swensen A, et al. Prevalence and outcomes of diabetes, hypertension and cardiovascular disease in COPD. Eur Respir J. 2008;32:962-9.

44. Soriano JB, Visick GT, Muellerova H, et al. Patterns of comorbidities in newly diagnosed COPD and asthma in primary care. Chest. 2005;128:2099-107.

45. Janda S, Park K, FitzGerald JM, et al. Statins in COPD: a systematic review. Chest. 2009;136:734-43.

46. Mancini GB, Etminan M, Zhang B, et al. Reduction of morbidity and mortality by statins, angiotensin-converting enzyme inhibitors, and angiotensin receptor blockers in patients with chronic obstructive pulmonary disease. J Am Coll Cardiol. 2006;47:2554-60.

47. Leech JA, Dulberg C, Kellie S, et al. Relationship of lung function to severity of osteoporosis in women. Am Rev Respir Dis. 1990;141:68-71.

48. Ng TP, Niti M, Tan WC, et al. Depressive symptoms and chronic obstructive pulmonary disease: effect on mortality, hospital readmission, symptom burden, functional status, and quality of life. Arch Intern Med. 2007;167:60-7.
49. Skillrud DM, Offord KP, Miller RD. Higher risk of lung cancer in chronic obstructive pulmonary disease. A prospective, matched, controlled study. Ann Intern Med. 1986;105:503-7.

50. Soriano JB, Davis KJ, Coleman B, et al. The proportional Venn diagram of obstructive lung disease: two approximations from the United States and the United Kingdom. Chest. 2003;124:474-81.

51. Kim TB, Oh YM, Chang YS, et al. The reality of an intermediate type between asthma and COPD in practice. Respir Care 2012, In press.

52. Jo KW, Ra SW, Chae EJ, et al. Three phenotypes of obstructive lung disease in the elderly. Int J Tuberc Lung Dis. 2010;14: 14818.

53. Gibson PG, Simpson JL. The overlap syndrome of asthma and COPD: what are its features and how important is it? Thorax. 2009;64:728-35.

54. Hardin M, Silverman EK, Barr RG, et al. The clinical features of the overlap between COPD and asthma. Respir Res. 2011;12:127.

55. Diaz-Guzman E, Khosravi M, Mannino DM. Asthma, chronic obstructive pulmonary disease, and mortality in the U.S. population. COPD. 2011;8:400-7.

56. Ferrer M, Alonso J, Morera J, et al. Chronic obstructive pulmonary disease stage and health-related quality of life. The Quality of Life of Chronic Obstructive Pulmonary Disease Study Group. Ann Intern Med. 1997;127:1072-9.

57. Anthonisen NR, Wright EC, Hodgkin JE. Prognosis in chronic obstructive pulmonary disease. Am Rev Respir Dis. 1986;133: 14 20.

58. Jones PW. Health status and the spiral of decline. COPD. 2009; 6:5963.

59. Wise RA. The value of forced expiratory volume in $1 \mathrm{~s}$ decline in the assessment of chronic obstructive pulmonary disease progression. Am J Med. 2006;119:4-11.

60. Nishimura M, Makita H, Nagai K, et al. Annual change in pulmonary function and clinical phenotype in chronic obstructive pulmonary disease. Am J Respir Crit Care Med. 2012, In press

61. Scanlon PD, Connett JE, Waller LA, et al. Smoking cessation and lung function in mild-to-moderate chronic obstructive pulmonary disease. The Lung Health Study. Am J Respir Crit Care Med. 2000;161:381-90.

62. Tashkin DP, Celli B, Decramer M, et al. Bronchodilator responsiveness in patients with COPD. Eur Respir J. 2008;31:742-50.

63. Miller MR, Hankinson J, Brusasco V, et al. Standardisation of spirometry. Eur Respir J. 2005;26:319-38.

64. Lee JS, Huh JW, Chae EJ, et al. Response patterns to bronchodilator and quantitative computed tomography in chronic obstructive pulmonary disease. Clin Physiol Funct Imaging. 2012;32:12-8.

65. Calverley PM, Burge PS, Spencer S, et al. Bronchodilator reversibility testing in chronic obstructive pulmonary disease. Thorax. 2003;58:659-64.

66. Brutsche MH, Downs SH, Schindler C, et al. Bronchial hyperresponsiveness and the development of asthma and COPD in asymptomatic individuals: SAPALDIA cohort study. Thorax. 2006;61:671-7.

67. de Marco R, Accordini S, Marcon A, et al. Risk factors for chronic obstructive pulmonary disease in a European cohort of young adults. Am J Respir Crit Care Med. 2011;183:891-7.

68. Cooper CB. The connection between chronic obstructive pulmonary disease symptoms and hyperinflation and its impact on exercise and function. Am J Med. 2006;119:21-31.

69. Casanova $C$, Cote $C$, de Torres JP, et al. Inspiratory-to-total lung capacity ratio predicts mortality in patients with chronic obstructive pulmonary disease. Am J Respir Crit Care Med. 2005; 171:591-7.

70. Cotton DJ, Soparkar GR, Grahan BL. Diffusing capacity in the clinical assessment of chronic airflow limitation. Med Clin North Am. 1996;80:549-64. 
71. Kitaguchi Y, Fujimoto K, Kubo K, et al. Characteristics of COPD phenotypes classified according to the findings of HRCT. Respir Med. 2006;100:1742-52.

72. Dillard TA, Piantadosi S, Rajagopal KR. Determinants of maximum exercise capacity in patients with chronic airflow obstruction. Chest. 1989;96:267-71.

73. Mohsenifar Z, Lee SM, Diaz P, et al. Single-breath diffusing capacity of the lung for carbon monoxide: a predictor of $\mathrm{PaO}_{2}$, maximum work rate, and walking distance in patients with emphysema. Chest. 2003;123:1394-400.

74. National Emphysema Treatment Trial Research Group. Patients at high risk of death after lung-volume-reduction surgery. N Engl J Med. 2001;345:1075-83.

75. Kent BD, Mitchell PD, McNicholas WT. Hypoxemia in patients with COPD: cause, effects, and disease progression. Int J Chron Obstruct Pulmon Dis. 2011;6:199-208.

76. Nocturnal Oxygen Therapy Trial Group. Continuous or nocturnal oxygen therapy in hypoxemic chronic obstructive lung disease: a clinical trial. Nocturnal Oxygen Therapy Trial Group. Ann Intern Med. 1980;93:391-8.

77. Cooper R, Ghali J, Simmons BE, et al. Elevated pulmonary artery pressure. An independent predictor of mortality. Chest. 1991;99: $112-20$.

78. Oswald-Mammosser M, Weitzenblum E, Quoix E, et al. Prognostic factors in COPD patients receiving long-term oxygen therapy. Importance of pulmonary artery pressure. Chest. $1995 ; 107: 1193-8$.

79. Naeije R. Pulmonary hypertension and right heart failure in chronic obstructive pulmonary disease. Proc Am Thorac Soc. 2005;2:20-2.

80. Lee JH, Oh YM, Seo JB, et al. Pulmonary artery pressure in chronic obstructive pulmonary disease without resting hypoxaemia. Int J Tuberc Lung Dis. 2011;15:830-7.

81. Humbert M, Sitbon O, Simonneau G. Treatment of pulmonary arterial hypertension. N Engl J Med. 2004;351:1425-36.

82. Lee JH, Lee DS, Kim EK, et al. Simvastatin inhibits cigarette smoking-induced emphysema and pulmonary hypertension in rat lungs. Am J Respir Crit Care Med. 2005;172:987-93.

83. Lee YK, Oh YM, Lee JH, et al. Quantitative assessment of emphysema, air trapping, and airway thickening on computed tomography. Lung. 2008;186:157-65.

84. Han MK, Bartholmai B, Liu LX, et al. Clinical significance of radiologic characterizations in COPD. COPD. 2009;6:459-67.

85. Friedman PJ. Imaging studyies in emphysema. Proc Am Thorac Soc. 2008;5:494-500.

86. Yuan R, Hogg JC, Pare PD, et al. Prediction of the rate of decline in $\mathrm{FEV}_{1}$ in smokers using quantitative computed tomography. Thorax. 2009;64:944-9.
87. Lee JS, Huh JW, Chae EJ, et al. Predictors of pulmonary function response to treatment with salmeterol/fluticasone in patients with chronic obstructive pulmonary disease. J Korean Med Sci. 2011;26:379-85.

88. Haruna A, Muro S, Nakano Y, et al. CT scan findings of emphysema predict mortality in COPD. Chest. 2010;138:63540.

89. Martinez FJ, Foster G, Curtis JL, et al. Predictors of mortality in patients with emphysema and severe airflow obstruction. Am J Respir Crit Care Med. 2006;173:1326-34.

90. Han MK, Kazerooni EA, Lynch DA, et al. Chronic obstructive pulmonary disease exacerbations in the COPDGene study: associated radiologic phenotypes. Radiology. 2011;261:27482.

91. Kim WJ, Oh YM, Sung J, et al. CT scanning-based phenotypes vary with ADRB2 polymorphisms in chronic obstructive pulmonary disease. Respir Med. 2009;103:98-103.

92. Fishman A, Martinez F, Naunheim K, et al. A randomized trial comparing lung-volume-reduction surgery with medical therapy for severe emphysema. N Engl J Med. 2003;348:2059-73.

93. Lee JH, Lee YK, Kim EK, et al. Responses to inhaled long-acting beta-agonist and corticosteroid according to COPD subtype. Respir Med. 2009;104:542-9.

94. Loscalzo J, Kohane I, Barabasi AL. Human disease classification in the postgenomic era: a complex systems approach to human pathobiology. Mol Syst Biol. 2007;3:124.

95. Agusti A, Vestbo J. Current controversies and future perspectives in chronic obstructive pulmonary disease. Am J Respir Crit Care Med. 2011;184:507-13.

96. Bozinovski S, Hutchinson A, Thompson M, et al. Serum amyloid a is a biomarker of acute exacerbations of chronic obstructive pulmonary disease. Am J Respir Crit Care Med. 2008; 177:269-78.

97. Lomas DA, Silverman EK, Edwards LD, et al. Serum surfactant protein D is steroid sensitive and associated with exacerbations of COPD. Eur Respir J. 2009;34:95-102.

98. Lomas DA, Silverman EK, Edwards LD, et al. Evaluation of serum CC-16 as a biomarker for COPD in the ECLIPSE cohort. Thorax. 2008;63:1058-63.

99. • Agusti A, Sobradillo P, Celli B. Addressing the complexity of chronic obstructive pulmonary disease: from phenotypes and biomarkers to scale-free networks, systems biology, and P4 medicine. Am J Respir Crit Care Med. 2011;183:1129-37. This review article summarizes the complexity of COPD, the novel scientific strategy of systems biology and its potential clinical derivatives, P4 medicine (Personalized, Predictive, Preventive, and Participatory). 